\title{
Prevalence of diabetic comorbidities and knowledge and practices of foot care among diabetic patients: a cross-sectional study
}

This article was published in the following Dove Press journal: Diabetes, Metabolic Syndrome and Obesity:Targets and Therapy

\author{
Hamza Mohammad \\ Abdulghani' \\ Areej Salman AIRajeh² \\ Budoor Hussain AISalman² \\ Lulwah Sami AITurki² \\ Norah Sulaiman AINajashi ${ }^{2}$ \\ Mohammad Irshad ${ }^{2}$ \\ Khalid Hamad Alharbi ${ }^{3}$ \\ Yazeed Eid AIBalawi ${ }^{3}$ \\ Yazeed A AISuliman ${ }^{3}$ \\ Tauseef Ahmad ${ }^{2}$ \\ 'Department of Medical Education, \\ College of Medicine, King Saud \\ University, ${ }^{2}$ College of Medicine, \\ King Saud University, ${ }^{3}$ King Khalid \\ University Hospital, King Saud \\ University, Riyadh, Saudi Arabia
}

Correspondence: Hamza Mohammad Abdulghani

Department of Medical Education,

College of Medicine, King Saud

University, Riyadh, P.O. Box 230155,

Riyadh I I32I, Saudi Arabia

Tel +96696I 4699177

Fax +966 96I $467 \quad 1967$

Email hamzaabg@gmail.com
Background: Diabetes mellitus with comorbid complications constitute a major public health problem worldwide. The aim of this study was to evaluate the risk of comorbid complications with glycosylated hemoglobin levels and diabetes duration. Also assessed were patients' diabetic foot-care knowledge and practices.

Patients and methods: This was a quasiexperimental study. A total of 360 type 2 diabetes mellitus patients were interviewed at a government health care center in Riyadh, Saudi Arabia. Diabetic complications and $\mathrm{HbA}_{1 \mathrm{c}}$-level data were collected from hospital records. A standard questionnaire was used to assess their diabetic foot-care knowledge and practice.

Results: Of the type 2 diabetes mellitus patients, $32.5 \%$ had highly uncontrolled glycosylated hemoglobin $\left(\mathrm{HbA}_{1 \mathrm{c}}\right.$ ) levels $(\geq 8.6 \%)$ and $62.8 \%$ had had diabetes $>10$ years. The patients had comorbid complications, such as hypertension (61.4\%), dyslipidemia (58.6\%), retinopathy $(23.3 \%)$, heart disease (14.4\%), and severe foot complications (3.9\%). The majority of highly uncontrolled $\mathrm{HbA}_{1 \mathrm{c}}$-level patients had retinopathy (OR 8.90, $P=0.0001$ ), foot complications (OR 8.09, $P=0.0001$ ), dyslipidemia (OR 2.81, $P=0.010$ ), and hypertension (OR 2.0, $P=0.028$ ) compared to the controlled $\mathrm{HbA}_{1 \mathrm{c}}$-level $(<7 \%)$ group. Patients with diabetes $>10$ years also had higher prevalence of foot complications (OR 2.92, $P=0.0001$ ), retinopathy (OR 2.17, $P=0.011$ ), and hypertension (OR 1.67, $P=0.033$ ). From patient responses, physicians examined only $34.2 \%$ of patient feet and $36.7 \%$ of patients received physicians advice for foot care. About $70 \%$ of patients had knowledge of diabetic foot care; however, only $41.7 \%$ of patients always examined their feet, $41.4 \%$ washed feet with warm water, $31.4 \%$ carefully dried between the toes, and $33.1 \%$ were using foot-moisturizing substances. Conclusion: The prevalence of comorbid complications was higher in the Saudi population compared to other international studies. Also, foot-care practice was not satisfactory. Therefore, there is need of improvement and increased awareness among physicians and patients to check regularly for proper care of the diabetic foot to avoid diabetic foot-related complications.

Keywords: diabetic mellitus, comorbid complication, foot care, Saudi Arabia

\section{Introduction}

Diabetes mellitus (DM) is a progressive metabolic disorder characterized by hyperglycemia, mainly due to resistance or deficiency of insulin hormone. The prevalence of $\mathrm{DM}$ is gradually rising worldwide, and it is predicted to increase from 171 million in the year 2000 to 366 million during 2030. ${ }^{1}$ In a report of the World Health Organization, DM will be the seventh-leading cause of death worldwide in $2030 .^{2}$ About two-thirds of patients who attend primary health care centers have diabetic complications. ${ }^{3,4}$ The International Diabetes Federation Atlas recently reported that about $17.7 \%$ of the Saudi Arabia adult population suffered from DM. ${ }^{5}$ Saudi Arabia has become the first country 
with high diabetes prevalence in the Middle East. ${ }^{5}$ DM also enhances health complications manyfold, such as hypertension, heart disease, retinopathy, and foot complications in the long term. ${ }^{6,7}$ Therefore, physicians' primary aim in DM management is to maintain blood-glucose levels around the normal range and thus prevent or delay the onset of related complications. $^{8}$

The diabetic foot is a common complication of diabetes patients associated with an increase in age and diabetic duration. ${ }^{9,10}$ Diabetic foot complications are caused by many factors, such as peripheral neuropathy that leads to loss of sensation in the feet and peripheral vascular diseases that decrease blood supply to tissue and may cause infection and gangrene, increasing the risk of amputation. ${ }^{7}$ Diabetic foot complications are the major cause of hospitalization among diabetic patients, ${ }^{11}$ and impose major economic burdens on the community and patients. ${ }^{12}$ A Saudi National Diabetes Registry data-based study reported foot complications among $3.3 \%$ of diabetes patients, of whom $2.05 \%$ had a foot ulcer, $0.19 \%$ had gangrene, and $1.06 \%$ had had an amputation. ${ }^{10,13}$ Poor foot care and foot-care-knowledge deficiency are important risk factors for foot problems. ${ }^{14}$ In many studies, awareness of diabetic foot care has been correlated with a decrease in foot ulcers and amputation. ${ }^{15,16}$ However, to our knowledge, there has been no study to assess the knowledge and practice of diabetic patients with regard to diabetic foot care in Saudi Arabia. In the present study, we investigated the prevalence of comorbidities and assessed the knowledge and practice of diabetic foot care among Saudi diabetic patients.

\section{Patients and methods Data collection}

This was a cross-sectional descriptive study comprising 360 Saudi diabetic patients who attended two primary health care centers at King Khalid University Hospital and King Abdulaziz University Hospital, affiliated with King Saud University, Riyadh, Saudi Arabia, during December 2015 to September 2016. A systematic random-sampling technique was used to select every fourth patient in each clinic among those visiting for a routine diabetic checkup. Patients participation was entirely voluntary, and whoever agreed to participate in this study signed a consent form. All participants in this study were interviewed individually by research-team members.

\section{Instrument}

A standard bilingual (Arabic and English) questionnaire was prepared based on previous studies and guidelines after an extensive literature review. ${ }^{17-20}$ The questionnaire was reviewed by expert physicians and piloted on ten diabetic patients. Some suggested changes ware incorporated. The questionnaire comprised four parts: the first consisted of sociodemographic information, presence or absence of comorbidities, presence or absence of foot complications, types of medication used, and DM-control level in the form of glycosylated hemoglobin $\left(\mathrm{HbA}_{1 \mathrm{c}}\right)$; the second consisted of seven questions assessing physician roles in diabetic patients' foot-care; the third assessed patients' knowledge about their foot care; and the fourth asked about the foot-care practices of the patients. Second-part answers were collected as yes/no, third-part answers as true/false, and fourth-part answers were collected on a 4-point Likert scale (always [3], sometimes [2], rarely [1], and never [0]). Patients' $\mathrm{HbA}_{\mathrm{lc}}$ level was collected from their hospital-database records and categorized into three levels (controlled [<7.0\%], uncontrolled [7.0\%-8.5\%], and highly uncontrolled $[\geq 8.6 \%]$ ). The criterion for good knowledge of foot care was a median score or above on the knowledge questions, while that for poor knowledge of foot care was a score below the median on the knowledge questions.

\section{Statistical analysis}

Data were entered into Microsoft Excel software and analyzed using SPSS version 21.0 (IBM, Armonk, NY, USA). The $\chi^{2}$ test was used to measure associations among the different categorical variables. $P<0.05$ was considered statically significant.

\section{Ethical approval}

All participants were informed of the objectives of the study, and the items in the questionnaire were explained. The research ethics committee of the Faculty of Medicine at King Saud University approved the study.

\section{Results}

Table 1 shows the demographic information of the type 2 DM (T2DM) patients. A total of 360 patients were interviewed, of which $37.2 \%$ were males and $62.8 \%$ females. The majority of the patients $(62.8 \%)$ had had T2DM $>10$ years. Patient ages were 18-75 years, and most female patients were younger than the male patients $(P=0.001)$. Most patients were married. Of these, the percentage of females married and divorced/widowed was high $(P=0.0001)$. About $26 \%$ of patients had uncontrolled $\mathrm{HbA}_{1 \mathrm{c}}$ levels, whereas $32.5 \%$ patients had highly uncontrolled $\left(\mathrm{HbA}_{1 \mathrm{c}} \geq 8.6 \%\right)$ levels. Medications used for the treatment of DM were 
Table I Demographic information of diabetic patients $(n=360)$

\begin{tabular}{|c|c|c|c|c|c|}
\hline & & Patients (360), n (\%) & Male (134), n (\%) & Female (226), n (\%) & $\chi^{2}(P)$ \\
\hline \multirow[t]{4}{*}{ Age group, years } & $18-30$ & $21(5.8)$ & $8(6.0)$ & $13(5.8)$ & $16.35(0.001)$ \\
\hline & $31-45$ & $44(12.2)$ & $13(9.7)$ & 31 (13.7) & \\
\hline & $46-60$ & 177 (49.2) & $52(38.8)$ & $125(55.3)$ & \\
\hline & $6 \mathrm{I}-75$ & $118(32.8)$ & $6 \mathrm{I}(45.5)$ & $57(25.2)$ & \\
\hline \multirow[t]{3}{*}{ Marital status } & Married & $299(83.1)$ & $124(92.5)$ & $175(77.4)$ & $22.24(0.000 I)$ \\
\hline & Single & $18(5.0)$ & $8(6.0)$ & $10(4.4)$ & \\
\hline & Divorced/widowed & $42(11.7)$ & $2(1.5)$ & $40(17.7)$ & \\
\hline \multirow[t]{2}{*}{ Duration of diabetes } & $>10$ years & $226(62.8)$ & $89(66.4)$ & $137(60.6)$ & $1.21(0.27)$ \\
\hline & $\leq 10$ years & $134(37.2)$ & $45(33.6)$ & $89(39.4)$ & \\
\hline \multirow[t]{3}{*}{ HBA $_{\mid c}{ }^{a}$} & Controlled & I 49 (4I.4) & $57(42.5)$ & $92(40.7)$ & $0.256(0.880)$ \\
\hline & Uncontrolled & $94(26.1)$ & $33(24.6)$ & $61(27.0)$ & \\
\hline & Highly uncontrolled & $117(32.5)$ & $44(32.8)$ & $73(32.3)$ & \\
\hline \multirow[t]{3}{*}{ Diabetes treatment } & Diet/oral agent & $209(58.3)$ & $68(50.7)$ & $142(62.8)$ & $6.48(0.039)$ \\
\hline & Insulin & $67(18.6)$ & $33(24.6)$ & $34(15.0)$ & \\
\hline & Insulin oral agent & $83(23.1)$ & $33(24.6)$ & $50(22.1)$ & \\
\hline \multirow[t]{4}{*}{ Foot complication } & Numbness & $9(2.5)$ & $8(6.0)$ & $6(2.7)$ & $2.630(0.269)$ \\
\hline & History of healed ulcer & $4(1.12)$ & $31(23.1)$ & $50(22.1)$ & \\
\hline & One toe amputation & $\mathrm{I}(0.27)$ & & & \\
\hline & None & $346(96.12)$ & 95 (70.9) & $170(75.2)$ & \\
\hline \multirow[t]{2}{*}{ Hypertension } & Yes & $22 I(6 I .4)$ & $77(57.5)$ & I 44 (63.7) & $1.39(0.239)$ \\
\hline & No & $139(38.6)$ & $57(42.5)$ & $82(36.3)$ & \\
\hline \multirow[t]{2}{*}{ Heart disease } & Yes & $52(14.4)$ & $26(19.4)$ & $26(11.5)$ & $4.247(0.039)$ \\
\hline & No & $308(85.6)$ & $108(80.6)$ & $200(88.5)$ & \\
\hline \multirow[t]{2}{*}{ Dyslipidemia } & Yes & $209(58.1)$ & $53(39.6)$ & $156(69.0)$ & $30.01(0.0001)$ \\
\hline & No & I5I (4I.9) & $81(60.4)$ & $70(31.0)$ & \\
\hline \multirow[t]{2}{*}{ Retinopathy } & Yes & $84(23.3)$ & $27(20.1)$ & $57(25.2)$ & $I .2 I(0.27 I)$ \\
\hline & No & $276(76.7)$ & 107 (79.9) & $169(74.8)$ & \\
\hline
\end{tabular}

Notes: a ${ }^{H B A}$ categories: control level ( $\left.<7.0 \%\right)$, uncontrolled level $(7.0 \%-8.5 \%)$, and highly uncontrolled level $(\geq 8.6 \%)$.

Abbreviation: $\mathrm{HBA}_{\mathrm{lc}}$, glycosylated hemoglobin.

oral hypoglycemic agents (OHAs) with controlled diet (58.3\%), insulin and OHAs (23.1\%), and insulin injections alone $(18.6 \%)$. Compared to male patients, a high percentage of female patients were taking OHAs with diet control $(P=0.04)$. Diabetic patients also had many diabetes-related comorbidities. About $3.9 \%$ of diabetic patients had foot complications. Of these, male patients had more foot complications than females; however, the difference was not significant. More than 58\% patients had dyslipidemia, and the percentage of female patients was significantly higher than the male patients $(P=0.0001)$.

Table 2 shows a multivariate analysis of $\mathrm{HbA}_{\mathrm{lc}}$ levels and diabetic duration with associated comorbid diseases. The history of foot complication was significantly higher in both uncontrolled $\mathrm{HbA}_{1 \mathrm{c}}$ (OR 2.76, $P=0.008$ ) and highly uncontrolled $\mathrm{HbA}_{1 \mathrm{c}}$ patients (OR 8.09, $P=0.0001$ ) compared to the controlled $\mathrm{HbA}_{1 \mathrm{c}}$ group. Also, dyslipidemia significantly increased with increased $\mathrm{HbA}_{1 \mathrm{c}}$ levels (uncontrolled $\mathrm{HbA}_{1 \mathrm{c}}$ OR 2.14, $P=0.01$; highly uncontrolled $\mathrm{HbA}_{1 \mathrm{c}} \mathrm{OR}$ $2.81, P=0.0001)$. Hypertension prevailed among $61.4 \%$ of patients, and the percentage was significantly high in the case of highly uncontrolled $\mathrm{HbA}_{1 \mathrm{c}}(\mathrm{OR} 2.00, P=0.028)$. The frequency of retinopathy was only $23.3 \%$ of the patients, but ORs were significantly high in both uncontrolled $\mathrm{HbA}_{1 \mathrm{c}}(\mathrm{OR}$ 8.89, $P=0.0001$ ) and highly uncontrolled $\mathrm{HbA}_{1 \mathrm{c}}(\mathrm{OR} 8.90$, $P=0.0001$ ) compared to controlled $\mathrm{HbA}_{1 \mathrm{c}}$ patients. Patients with diabetes $>10$ years also had more complications in the feet (OR 2.92, $P=0.0001$ ), retinopathy (OR 2.17, $P=0.011$ ), and hypertension (OR 1.67, $P=0.033$ )

Table 3 showed diabetic patients' foot-care practices. Only $41.7 \%$ always examined their feet regularly, $41.4 \%$ always washed their feet with warm water, $31.4 \%$ always carefully dried between the toes after washing, $33.1 \%$ always moisturized their feet, and $65.8 \%$ regularly cut their toenails. On the negative side, $2.8 \%$ always walked barefoot outside the house. Of these, male patients' foot-care management was significantly low compared to female patients, because the majority of them were always walking outside barefoot $(4.5 \%, P=0.0001)$. However, a high percentage of male patients always inspected their feet $(50.0 \%)$, checked their 
Table 2 Multiple-variable analysis of diabetes-associated comorbid diseases

\begin{tabular}{|c|c|c|c|c|c|c|c|c|c|}
\hline \multirow[t]{2}{*}{ Problems } & \multicolumn{3}{|c|}{$\mathrm{HBA}_{\mathrm{Ic}}$ (uncontrolled) $^{\mathrm{a}}$} & \multicolumn{3}{|c|}{ HBA $_{\text {Ic }}$ (highly uncontrolled) ${ }^{a}$} & \multicolumn{3}{|c|}{ DM duration $>10$ years ${ }^{b}$} \\
\hline & $\overline{\text { OR }}$ & $95 \% \mathrm{Cl}$ & $P$ & $\overline{O R}$ & $95 \% \mathrm{Cl}$ & $P$ & $\overline{O R}$ & $95 \% \mathrm{Cl}$ & $P$ \\
\hline Foot problems ${ }^{c}$ & 2.76 & $1.30-5.84$ & 0.008 & 8.09 & $4.01-16.32$ & 0.0001 & 2.92 & $1.63-5.23$ & 0.0001 \\
\hline Hypertension & 1.17 & $0.65-2.09$ & 0.603 & 2.00 & $1.08-3.70$ & 0.028 & 1.67 & $1.04-2.67$ & 0.033 \\
\hline Heart disease & 2.16 & $0.86-5.38$ & 0.100 & 2.35 & $0.94-5.85$ & 0.066 & 1.75 & $0.83-3.67$ & 0.140 \\
\hline Dyslipidemia & 2.14 & $1.20-3.84$ & 0.010 & 2.81 & $1.53-5.15$ & 0.001 & 1.11 & $0.69-1.78$ & 0.663 \\
\hline Retinopathy & 8.89 & $3.8 I-20.78$ & 0.0001 & 8.90 & $3.75-21.15$ & 0.0001 & 2.17 & $1.20-3.94$ & 0.011 \\
\hline
\end{tabular}

Notes: ${ }^{a}$ Reference controlled HBA level; breference diabetic duration <10 years; cboth severe and mild.

Abbreviations: $\mathrm{HBA}_{\mathrm{Ic}}$, glycosylated hemoglobin; DM, diabetes mellitus.

shoes before wear (45.5\%), and used cotton socks (38.8\%, $P<0.050)$. Regarding patients' compliance with foot examination, the majority of patients self-examined or inspected their feet regularly, and their percentage was significantly higher than the no-foot-problem patients $(P=0.05)$. For the query related to the physician's role in diabetic patients' foot care, only $34.2 \%$ of patients agreed that the physician examined their feet, whereas only $36.7 \%$ of patients agreed that they got foot-care advice from their physicians during routine checkups.

Table 4 presents the effect of physician advice and patients knowledge of foot-care practices. About $70 \%$ of patients had good knowledge scores: equal to or more than the median score. Table S1 shows patients' knowledge of individual items related to diabetic foot care. The results inferred that foot-care practice was high among the group of patients who got advice from their physicians. Their foot-care practice was significantly high for "carefully dry between toes after washing feet" $(P=0.0001)$ and "moisturizing feet daily" $(P=0.013)$ compared to the no-advice group. Similarly, patients' with good foot-care knowledge showed a positive effect on footcare practices compared to the poor-knowledge group.

\section{Discussion}

This is one of the few studies in Saudi Arabia to address DMassociated comorbidity and awareness of diabetic foot-care practice. In this study, about a third of patients had highly uncontrolled T2DM and about $63 \%$ had had it for $>10$ years. The prevalence of diabetes was higher in the female and younger age group than the male participants of the similar age group, and this fact has also been reported in other international and local studies. ${ }^{1,4} \mathrm{~A}$ sedentary lifestyle or physical inactivity might be one of the associated factors of uncontrolled $\mathrm{HbA}_{1 \mathrm{c}}$ levels in the Saudi population. One local study found that $>50 \%$ of those in younger age-groups were physically inactive, with the most common obstacles preventing physical activity hot weather during most of the year, lack of appropriate social culture, and affordable physical activity facilities and outdoor spaces for activities, particularly for women. ${ }^{21}$

Defects in insulin action simultaneously increase bloodglucose levels, consequently leading to a higher amount of lipoprotein synthesis. ${ }^{22}$ Therefore, the prevalence of dyslipidemia among the study population was higher than the nondiabetic Saudi population, ${ }^{23}$ as the majority $(\sim 58 \%)$ of the patients had dyslipidemia. The prevalence of dyslipidemia among the DM patients has varied in different studies, and its frequency is up to $88 \%$ of diabetes population. ${ }^{24,25}$ As with another study, the prevalence of dyslipidemia was higher for uncontrolled $\mathrm{HbA}_{1 \mathrm{c}}$ patients. ${ }^{26}$ Also, the frequency of dyslipidemia is constantly increasing in Saudi diabetic patients. In 1995 , al-Nuaim et $\mathrm{al}^{27}$ reported only $14 \%$ of diabetic patients with hypercholesterolemia, whereas in 1998 al-Ghamdi and $\operatorname{Rehman}^{28}$ reported $26 \%$ of the diabetic population had hypercholesterolemia.

Uncontrolled hyperglycemia with dyslipidemia causes many health complications, including dysfunction of multiple organs. ${ }^{29}$ As per previous research, the frequency of hypertension was high among the patients and higher among those who had an uncontrolled $\mathrm{HbA}_{1 \mathrm{c}}$ level. ${ }^{26,30,31}$ The prevalence of retinopathy and heart diseases as comorbidities among our DM patients was less than the previous local study. ${ }^{32}$ However, a higher frequency of DM patients with dyslipidemia reported cardiovascular complications. More than a quarter of diabetic retinopathy patients were hypertensive and had dyslipidemia. Similarly to our study, other studies have also reported that hypertension and dyslipidemia were associated with substantially increased cardiovascular disease and retinopathy. ${ }^{33,34}$ In the present study, female patients had more dyslipidemia and suffered from more hypertension and retinopathy complications than male patients. These results were consistent with previous local and international findings. ${ }^{3,35}$ 
Table 3 Diabetic patients' self-practice of foot care

\begin{tabular}{|c|c|c|c|c|c|c|}
\hline Items & Categories & & Never, n (\%) & Sometimes, n (\%) & Always, n(\%) & $\chi^{2}(P)$ \\
\hline Do you examine/ & Sex & Male & $20(14.9)$ & $47(35.1)$ & $67(50.0)$ & $6.27(0.043)$ \\
\hline inspect your feet on & & Female & $47(20.8)$ & $96(42.5)$ & $83(36.7)$ & \\
\hline \multirow[t]{3}{*}{ a regular basis, daily? } & Foot & Yes & $19(20.0)$ & $28(29.5)$ & $48(50.5)$ & $5.98(0.050)$ \\
\hline & complications & No & $48(18.1)$ & $115(43.4)$ & $102(38.5)$ & \\
\hline & & Total & $67(18.6)$ & $143(39.7)$ & $150(4 \mid .7)$ & \\
\hline Do you check your & Sex & Male & $32(23.9)$ & $41(30.6)$ & $61(45.5)$ & $8.46(0.015)$ \\
\hline shoes before you & & Female & $87(38.5)$ & $61(27.0)$ & $78(34.5)$ & \\
\hline \multirow[t]{3}{*}{ put them on? } & Foot & Yes & $33(34.7)$ & $25(26.3)$ & $37(38.9)$ & $0.30(0.86 \mathrm{I})$ \\
\hline & complications & No & $86(32.5)$ & $77(29.1)$ & $102(38.5)$ & \\
\hline & & Total & $119(33.1)$ & $102(28.3)$ & $139(38.6$ & \\
\hline Do you walk & Sex & Male & $102(76.1)$ & $26(29.4)$ & $6(4.5)$ & $17.90(0.0001)$ \\
\hline \multirow[t]{4}{*}{ outside barefoot? } & & Female & $208(92.0)$ & $14(6.2)$ & $4(1.8)$ & \\
\hline & Foot & Yes & 79 (83.2) & $13(13.7)$ & $3(3.2)$ & $0.97(0.617)$ \\
\hline & complications & No & $231(87.2)$ & $27(10.2)$ & $7(2.6)$ & \\
\hline & & Total & $310(86.1)$ & 40 (II.I) & $10(2.8)$ & \\
\hline Do you wash your & Sex & Male & $14(10.4)$ & $66(49.3)$ & $54(40.3)$ & $4.07(0.130)$ \\
\hline feet with warm & & Female & II (4.9) & $120(53.1)$ & $95(42.0)$ & \\
\hline \multirow[t]{3}{*}{ water daily? } & Foot & Yes & $7(7.4)$ & $43(45.3)$ & $45(47.3)$ & $2.17(0.337)$ \\
\hline & complications & No & $18(6.8)$ & I $43(54.0)$ & $104(39.2)$ & \\
\hline & & Total & $25(6.9)$ & $186(51.7)$ & $149(4 \mid .4)$ & \\
\hline Do you carefully dry & Sex & Male & $50(37.3)$ & $36(29.9)$ & $48(35.8)$ & $1.97(0.374)$ \\
\hline between toes after & & Female & $92(40.7)$ & $69(30.5)$ & $65(28.8)$ & \\
\hline \multirow[t]{3}{*}{ washing your feet? } & Foot & Yes & $36(37.9)$ & $27(28.4)$ & $32(33.7)$ & $0.320(0.852)$ \\
\hline & complications & No & $106(40.0)$ & $78(29.4)$ & $81(30.6)$ & \\
\hline & & Total & $142(39.4)$ & $105(29.2)$ & $113(3 \mid .4)$ & \\
\hline Do you moisturize & Sex & Male & $40(29.9)$ & $56(41.8)$ & $38(28.4)$ & $16.75(0.000 \mathrm{I})$ \\
\hline your feet (put & & Female & $28(12.4)$ & $117(51.8)$ & $81(35.8)$ & \\
\hline \multirow[t]{3}{*}{ cream on) daily? } & Foot & Yes & $16(16.8)$ & $42(44.2)$ & $37(38.9)$ & $2.04(0.361)$ \\
\hline & complications & No & $52(19.6)$ & 131 (49.4) & $82(30.9)$ & \\
\hline & & Total & $68(18.9)$ & $173(48.1)$ & $119(33.1)$ & \\
\hline Do you & Sex & Male & $9(6.7)$ & $73(54.5)$ & $52(38.8)$ & $22.09(0.0001)$ \\
\hline continuously wear & & Female & $61(27.0)$ & $95(42.0)$ & $70(31.0)$ & \\
\hline \multirow[t]{3}{*}{ cotton socks? } & Foot & Yes & $13(13.7)$ & $50(52.6)$ & $32(33.7)$ & $3.18(0.203)$ \\
\hline & complications & No & $57(21.5)$ & II 8 (44.5) & $90(34.0)$ & \\
\hline & & Total & $70(19.4)$ & $168(46.7)$ & $122(33.9)$ & \\
\hline Do you cut your & Sex & Male & $2(1.5)$ & $40(29.9)$ & 92 (68.7) & $0.83(0.569)$ \\
\hline toenails every 2 & & Female & $3(1.3)$ & $78(34.5)$ & $145(64.2)$ & \\
\hline \multirow[t]{2}{*}{ weeks? } & Foot & Yes & $2(2.1)$ & $30(31.6)$ & $63(66.3)$ & $0.54(0.764)$ \\
\hline & complications & No & $3(1.1)$ & $88(33.2)$ & 174 (65.7) & \\
\hline Total & & & $5(1.4)$ & $118(32.8)$ & $273(65.8)$ & \\
\hline
\end{tabular}

Our study results also confirm the prevalence of DMassociated comorbidities was higher among patients who had had diabetes $>10$ years, similarly to other studies. ${ }^{26,36,37}$ The overall cumulative effect of dyslipidemia, hypertension, retinopathy, and diabetic duration leads to occlusive arterial disease that results in ischemia in the lower extremity and an increased risk of foot ulcers, gangrene, and amputation. ${ }^{38,39}$ However, in the present study, major foot complications among the patients were fewer and almost similar to a previous cohort study, in which $3.5 \%$ of diabetic patients had foot ulcers and gangrene. ${ }^{10}$ Conversely, an international study found that about $15 \%-25 \%$ of diabetic patients were at risk of developing foot ulcers during their lifetime, ${ }^{15}$ though the incidence of foot ulceration in Western countries is around $2 \%$ annually. ${ }^{40}$

Many diabetes-care organizations and researchers recommend serious timely intervention in the form of diabetic foot-care awareness, dietary instructions, and physical exercises. A majority of diabetic foot complications can be prevented by patient foot-care practices on a regular basis. ${ }^{41,42}$ Contrary to this recommendation, in the present study, only $41.7 \%$ of diabetic patients' self-examined their 
Table 4 Effect of physician advice and patient knowledge on foot-care practices

\begin{tabular}{|c|c|c|c|c|c|c|c|}
\hline \multirow[t]{2}{*}{ Item } & \multirow[t]{2}{*}{ Response } & \multicolumn{3}{|c|}{ Physician advice } & \multicolumn{3}{|c|}{ Foot-care knowledge } \\
\hline & & $\begin{array}{l}\text { Yes (132), } \\
\text { n (\%) }\end{array}$ & $\begin{array}{l}\text { No (228), } \\
\text { n (\%) }\end{array}$ & $\chi^{2}(P)$ & $\begin{array}{l}\text { Good (25I), } \\
\text { n (\%) }\end{array}$ & $\begin{array}{l}\text { Poor (1 09), } \\
\text { n (\%) }\end{array}$ & $\chi^{2}(P)$ \\
\hline Do you examine/inspect your & Yes & $113(85.6)$ & $180(78.9)$ & $2.45(0.118)$ & $208(82.9)$ & $85(78.0)$ & $1.19(0.274)$ \\
\hline feet on a regular basis, daily? & No & $19(14.4)$ & $48(21.1)$ & & $43(17.1)$ & $24(22.0)$ & \\
\hline Do you check your shoes & Yes & 87 (65.9) & $154(67.5)$ & $0.10(0.75 \mathrm{I})$ & $179(7 \mid .3)$ & $62(56.9)$ & $7.15(0.007)$ \\
\hline before you put them on? & No & $45(34.1)$ & $74(32.5)$ & & $72(28.7)$ & $47(43.1)$ & \\
\hline Do you check your shoes when & Yes & $80(60.6)$ & $143(62.7)$ & $0.16(0.691)$ & $163(64.9)$ & $60(55.0)$ & $3.15(0.076)$ \\
\hline you take them off? & No & $52(39.4)$ & $85(37.7)$ & & $88(35.1)$ & $49(45.0)$ & \\
\hline \multirow[t]{2}{*}{ Do you walk outside barefoot? } & Yes & $5(3.8)$ & $5(2.2)$ & $0.79(0.375)$ & $6(2.4)$ & $4(3.7)$ & $0.46(0.497)$ \\
\hline & No & $127(96.2)$ & $223(97.8)$ & & $245(97.6)$ & $105(96.3)$ & \\
\hline Do you wash your feet with & Yes & $124(93.9)$ & $211(92.5)$ & $0.25(0.616)$ & $231(92.0)$ & $104(95.4)$ & $1.34(0.246)$ \\
\hline warm water daily? & No & $8(6.1)$ & $17(7.5)$ & & $20(8.0)$ & $5(4.6)$ & \\
\hline Do you careful dry between the & Yes & $98(74.2)$ & $120(52.6)$ & $16.35(0.0001)$ & $155(61.8)$ & $63(57.8)$ & $0.50(0.48 \mathrm{I})$ \\
\hline toes after washing your feet? & No & $34(25.8)$ & $108(47.4)$ & & $96(38.2)$ & $46(42.2)$ & \\
\hline Do you moisturize your feet & Yes & $116(87.9)$ & $176(77.2)$ & $623(0.013)$ & $205(81.7)$ & $87(79.8)$ & $0.17(0.679)$ \\
\hline (put cream on) daily? & No & $16(12.1)$ & $52(22.8)$ & & $46(18.3)$ & $22(20.2)$ & \\
\hline Do you continuously wear & Yes & $110(83.3)$ & $180(78.9)$ & $\mathrm{I} .02(0.3 \mathrm{II})$ & $210(83.7)$ & $80(73.4)$ & $5.11(0.024)$ \\
\hline cotton socks? & No & $22(16.7)$ & $48(2 \mathrm{I} . \mathrm{I})$ & & $4 \mid(16.3)$ & $29(26.6)$ & \\
\hline Do you cut your toenails every & Yes & $132(100)$ & $223(97.8)$ & $2.93(0.087)$ & $248(98.8)$ & $107(98.2)$ & $0.22(0.634)$ \\
\hline 2 weeks? & No & 0 & $5(2.2)$ & & $3(1.2)$ & $2(1.8)$ & \\
\hline
\end{tabular}

feet. Almost the same figure was reported in a previous local study. ${ }^{43}$ Also, only a third of patients had their feet examined by a physician or received advice from their physicians about foot care. These data were also almost similar to previous local studies. ${ }^{43,44}$ Patients' foot examination and advice regarding foot care from attending physicians will increase patients' confidence in managing their foot-care practices..$^{20,41}$

Furthermore, in this study, the majority of patients had good knowledge of diabetic foot care, more so than other studies. ${ }^{19,20}$ Also, foot-care practice was high among patients who had good foot-care knowledge and got advice from their physicians. However, the results did not show significant differences from the poor-knowledge and notadvised groups. Here, the results should be interpreted with caution, because Muslims wash their feet and toes at least five times a day for their prayers. In this study, few patients had indoor and outdoor barefoot-walking habits, though these patients were much fewer compared to other studies reported elsewhere. ${ }^{45,46}$ Of these patients, the majority had poor knowledge and did not get advice from their physicians. Physicians should advise not walking barefoot inside home and that walking outside the home can be disastrous. Patients from rural areas, of low economic and poor educational status, and other sociodemographic factors could lead to such practice, which in turn can result in ulcer development or even toe or lower-extremity amputations.
It is well known that good knowledge will lead to healthy behavior, but some people may still engage in unhealthy behavior despite knowledge of their risk. ${ }^{47}$ Therefore, this study suggests an improvement in or increased awareness and practice of diabetic foot care by patients as well as health care providers. Physicians are an important source of information, and have a leading role to play in increasing awareness among patients regarding foot self-care. Therefore, our study recommends that physicians taking care of diabetic patients check their patients' feet routinely and improve patients' knowledge about foot self-care.

This study also recommends that hospital management organizes frequent training programs for primary health care physicians involved in diabetes management. This could be an effective way to increase knowledge of diabetic foot management and complications, as well as awareness among diabetic patients, as reported by another study. ${ }^{48}$

\section{Conclusion}

We found that about a third of participants suffered from highly uncontrolled DM and half had other comorbidities. Despite this, only a third of patients reported their feet had been examined at clinics or receiving advice on foot care from their physician. On the other hand, the majority of patients had knowledge of diabetic foot care, but few actually practiced proper foot care. Therefore, there is an urgent need for additional efforts for diabetic patients and their physicians for 
regular checkups of patients' feet and promoting appropriate foot care among patients.

\section{Limitations}

A few limitations of our study should be kept in mind. First, all information regarding the patients was based on interviews and their hospital records. Second, this study was conducted only among patients living in Saudi Arabia.

\section{Acknowledgments}

The authors are thankful to Dr Mohammed AlHarbi for his extensive support in collection of data by interviewing patients and advising on data analysis. Also, we would like to thank Dr Nehal Khamis for his revision of the final study draft and improving the manuscript to its final shape. This work was funded by the College of Medicine Research Center, Deanship of Scientific Research, King Saud University, Riyadh, Saudi Arabia.

\section{Disclosure}

The authors report no conflicts of interest in this work.

\section{References}

1. Wild S, Roglic G, Green A, Sicree R, King H. Global prevalence of diabetes: estimates for the year 2000 and projections for 2030. Diabetes Care. 2004;27(5):1047-1053.

2. Mathers CD, Loncar D. Projections of global mortality and burden of disease from 2002 to 2030. PLoS Med. 2006;3(11):e442.

3. Khan AR, Lateef ZN, Fatima S, Al Yousuf SA, Afghan SZ, al Marghani S. Prevalence of chronic complication among type 2 diabetics attending primary health care centers of Al Ahsa district of Saudi Arabia: a cross sectional survey. Glob J Health Sci. 2014;6(4):245-253.

4. Alqurashi KA, Aljabri KS, Bokhari SA. Prevalence of diabetes mellitus in a Saudi community. Ann Saudi Med. 2011;31(1):19-23.

5. International Diabetes Federation. IDF Diabetes Atlas. 6th ed. Brussels: IDF; 2017

6. Khawaja N, abu-Shennar J, Saleh M, Dahbour SS, Khader YS, Ajlouni $\mathrm{KM}$. The prevalence and risk factors of peripheral neuropathy among patients with type 2 diabetes mellitus: the case of Jordan. Diabetol Metab Syndr. 2018;10:8.

7. Amin N, Doupis J. Diabetic foot disease: from the evaluation of the "foot at risk" to the novel diabetic ulcer treatment modalities. World $J$ Diabetes. 2016;7(7):153-164.

8. Goldstein BJ, Gomis R, Lee HK, Leiter LA. Type 2 diabetes: treat early, treat intensively. Int J Clin Pract Suppl. 2007;61(157):16-21.

9. Mason J, O'Keeffe C, Hutchinson A, Mcintosh A, Young R, Booth A. A systematic review of foot ulcer in patients with type 2 diabetes mellitus - II: treatment. Diabet Med. 1999;16(11):889-909.

10. al-Rubeaan K, al Derwish M, Ouizi S, et al. Diabetic foot complications and their risk factors from a large retrospective cohort study. PLoS One. 2015;10(5):e0124446.

11. Pinzur MS, Slovenkai MP, Trepman E, Shields NN. Guidelines for diabetic foot care: recommendations endorsed by the Diabetes Committee of the American Orthopaedic Foot and Ankle Society. Foot Ankle Int. 2005;26(1):113-119.

12. Gordois A, Scuffham P, Shearer A, Oglesby A, Tobian JA. The health care costs of diabetic peripheral neuropathy in the US. Diabetes Care. 2003;26(6):1790-1795.

13. Alzahrani HA. Diabetes-related lower extremities amputations in Saudi Arabia: the magnitude of the problem. Ann Vasc Dis. 2012;5(2):151-156.
14. Chandalia HB, Singh D, Kapoor V, Chandalia SH, Lamba PS. Footwear and foot care knowledge as risk factors for foot problems in Indian diabetics. Int J Diabetes Dev Ctries. 2008;28(4):109-113.

15. Boulton AJ. The diabetic foot: preface. Med Clin North Am. 2013;97(5):xiii-xiv.

16. de Sá PN, Moura JR, Júnior EB, de Almeida PC, de Macêdo SF, da Silva AR. [Knowledge, attitudes, and practices for the prevention of diabetic foot]. Rev Gaucha Enferm. 2014;35(3):36-42. Portuguese.

17. Lamchahab FZ, el Kihal N, Khoudri I, Chraibi A, Hassam B, ait Ourhroui M. Factors influencing the awareness of diabetic foot risks. Ann Phys Rehabil Med. 2011;54(6):359-365.

18. Hasnain S, Sheikh NH. Knowledge and practices regarding foot care in diabetic patients visiting diabetic clinic in Jinnah Hospital, Lahore. J Pak Med Assoc. 2009;59(10):687-690.

19. Mabrouk N, Abdou M, Nour-Eldin H, el-Foly AAS, Omar SA. Knowledge, attitude, and practice of family physicians regarding diabetic neuropathy in family practice centers: Suez Canal University. Int J Med Public Health. 2013;3(4):230-234.

20. Seid A, Tsige Y. Knowledge, practice, and barriers of foot care among diabetic patients attending Felege Hiwot Referral Hospital, Bahir Dar, northwest Ethiopia. Adv Nurs. 2015;2015:934623.

21. al-Drees A, Abdulghani H, Irshad M, et al. Physical activity and academic achievement among the medical students: a cross-sectional study. Med Teach. 2016;38 Suppl 1:S66-S72.

22. Wilcox G. Insulin and insulin resistance. Clin Biochem Rev. 2005;26(2):19-39.

23. al-Kaabba AF, al-Hamdan NA, el Tahir A, Abdalla AM, Saeed AA, Hamza MA. Prevalence and correlates of dyslipidemia among adults in Saudi Arabia: results from a national survey. Open J Endocr Metab Dis. 2012;2(4):89-97.

24. Vijayaraghavan K. Treatment of dyslipidemia in patients with type 2 diabetes. Lipids Health Dis. 2010;9:144.

25. Dixit AK, Dey R, Suresh A, et al. The prevalence of dyslipidemia in patients with diabetes mellitus of ayurveda hospital. J Diabetes Metab Disord. 2014;13:58.

26. Momin AA, Bankar MP, Bhoite GM. Glycosylated hemoglobin (HbA1C): association with dyslipidemia and predictor of cardiovascular diseases in type 2 diabetes mellitus patients. Int $J$ Health Sci Res. 2013;3(8):40-46.

27. al-Nuaim AR, Famuyiwa O, Greer W. Hyperlipidemia among Saudi diabetic patients: pattern and clinical characteristics. Ann Saudi Med. 1995;15(3):240-243.

28. al-Ghamdi KS, Rehman R. Hyperlipidemia and obesity among diabetics at Jubail military hospital. J Family Community Med. 1998;5(1):45-50.

29. Rhim B, Harkless L. Prevention: can we stop problems before they arise? Semin Vasc Surg. 2012;25(2):122-128.

30. Akbar DH. Is hypertension common in hospitalized type 2 diabetic patients? Saudi Med J. 2001;22(2):139-141.

31. Thomas MC, Atkins R. Assessment and management of hypertension in patients with type 2 diabetes. Intern Med J. 2009;39(3):143-149.

32. Osaimi S, al-Gelban KS. Diabetes mellitus-prevalence and associated cardiovascular risk factors in a Saudi suburban community. Biomed Res. 2007;18:147-153.

33. Heydari I, Radi V, Razmjou S, Amiri A. Chronic complications of diabetes mellitus in newly diagnosed patients. Int $J$ Diabetes Mellit. 2010;2(1):61-63.

34. Snipelisky D, Ziajka P. Diabetes and dyslipidemia: a direct quantitative analysis. World J Cardiovasc Dis. 2012;2(1):20-25.

35. Sosale A, Kumar KM, Sadikot SM, et al. Chronic complications in newly diagnosed patients with type 2 diabetes mellitus in India. Indian J Endocrinol Metab. 2014;18(3):355-360.

36. Cortez DN, Reis IA, Souza DA, Macedo MM, Torres HD. Complications and the time of diagnosis of diabetes mellitus in primary care. Acta Paul Enferm. 2015;28(3):250-255.

37. Song SH, Hardisty CA. Early onset type 2 diabetes mellitus: a harbinger for complications in later years: clinical observation from a secondary care cohort. QJM. 2009;102(11):799-806. 
38. Clayton W, Elasy TA. A review of the pathophysiology, classification, and treatment of foot ulcers in diabetic patients. Clin Diabetes. 2009;27(2):52-58.

39. Ferguson TS, Tulloch-Reid MK, Younger NO, et al. Diabetic foot complications among patients attending a specialist diabetes clinic in Jamaica: prevalence and associated factors. West Indian Med J. 2013;62(3):216-223.

40. Boulton AJ [database on the Internet]. The diabetic foot. 2016. Available from: https://www.ncbi.nlm.nih.gov/books/NBK409609. Accessed June $21,2018$.

41. Holstein P, Ellitsgaard N, Olsen BB, Ellitsgaard V. Decreasing incidence of major amputations in people with diabetes. Diabetologia. 2000;43(7):844-847.

42. Cheer K, Shearman C, Jude EB. Managing complications of the diabetic foot. BMJ. 2009;339(339):b4905.

43. al-Asmary AS, Mostafa OS, al-Khaldi YM. Diabetic patients' knowledge and practice regarding prevention of diabetic foot. Med J Cairo Univ. 2013;81(2):197-205.
44. Şen HM, Şen H, Aşık M, et al. The importance of education in diabetic foot care of patients with diabetic neuropathy. Exp Clin Endocrinol Diabetes. 2015;123(3):178-181.

45. Jayasinghe SA, Atukorala I, Gunethilleke B, Siriwardena V, Herath SC, de Abrew K. Is walking barefoot a risk factor for diabetic foot disease in developing countries? Rural Remote Health. 2007;7(2):692.

46. Muhammad-Lutfi AR, Zaraihah MR, Anuar-Ramdhan IM. Knowledge and practice of diabetic foot care in an in-patient setting at a tertiary medical center. Malays Orthop J. 2014;8(3):22-26.

47. Nam S, Chesla C, Stotts NA, Kroon L, Janson SL. Barriers to diabetes management: patient and provider factors. Diabetes Res Clin Pract. 2011;93(1):1-9.

48. Murugesan N, Shobana R, Snehalatha C, Kapur A, Ramachandran A. Immediate impact of a diabetes training programme for primary care physicians: an endeavour for national capacity building for diabetes management in India. Diabetes Res Clin Pract. 2009;83(1): $140-144$. 


\section{Supplementary material}

Table SI Diabetic foot-care knowledge among patients

\begin{tabular}{|c|c|c|c|c|c|}
\hline Item & Response & Participants, n (\%) & Male, n (\%) & Female, n (\%) & $\chi^{2}(P)$ \\
\hline Look after their feet because they may & True & $308(85.6)$ & $124(92.5)$ & $184(8 \mid .4)$ & $8.42(0.004)$ \\
\hline not feel a minor injury to their feet & Do not know & $52(14.4)$ & $10(7.5)$ & $42(18.6)$ & \\
\hline Look after their feet because wounds & True & $343(95.3)$ & |3| (97.8) & $212(93.8)$ & $2.93(0.087)$ \\
\hline and infection may not heal quickly & Do not know & $17(4.7)$ & $3(2.2)$ & $14(6.2)$ & \\
\hline Look after their feet because they may & True & $342(95.0)$ & $129(96.3)$ & $213(94.2)$ & $0.72(0.395)$ \\
\hline get a foot ulcer & Do not know & $18(5.0)$ & $5(3.7)$ & $13(5.8)$ & \\
\hline Do not smoke because smoking causes & True & $326(90.6)$ & $127(94.8)$ & $199(88.1)$ & $4.45(0.035)$ \\
\hline poor circulation and affects the feet & Do not know & $34(9.4)$ & $7(5.2)$ & 27 (11.9) & \\
\hline Look after their feet because they are & True & $319(88.6)$ & $121(90.3)$ & $198(87.6)$ & $0.602(0.438)$ \\
\hline more prone to flat foot & Do not know & $41(11.4)$ & $13(9.7)$ & $28(12.4)$ & \\
\hline Take medication regularly because & True & $355(98.6)$ & $132(98.5)$ & $223(98.7)$ & $0.017(0.897)$ \\
\hline they are liable to get DM complication & Do not know & $5(1.4)$ & $2(1.5)$ & $3(1.3)$ & \\
\hline How often do you think you should & True & $328(91.1)$ & $123(9 \mid .8)$ & $205(90.7)$ & $0.64(0.725)$ \\
\hline $\begin{array}{l}\text { inspect the inside of your footwear for } \\
\text { objects or torn lining? }\end{array}$ & Do not know & $31(8.6)$ & II (8.2) & $20(8.8)$ & \\
\hline How often do you think you should & True & $343(95.3)$ & $126(94.0)$ & $217(96.0)$ & $0.739(0.390)$ \\
\hline need to wash your feet daily? & Do not know & $17(4.7)$ & $8(6.0)$ & $9(4.0)$ & \\
\hline What water temperature of do you & True & $277(79.9)$ & $104(77.6)$ & $173(76.5)$ & $0.054(0.817)$ \\
\hline think you should wash your feet in? & Do not know & $83(23.1)$ & $30(22.4)$ & $53(23.5)$ & \\
\hline How often do you think you should & True & $247(68.6)$ & $91(67.9)$ & $156(69.0)$ & $0.049(0.825)$ \\
\hline wear shoes and socks? & Do not know & II3 (3I.4) & $43(32.1)$ & $70(31.0)$ & \\
\hline
\end{tabular}

Diabetes, Metabolic Syndrome and Obesity: Targets and Therapy is an international, peer-reviewed open-access journal committed to the rapid publication of the latest laboratory and clinical findings in the fields of diabetes, metabolic syndrome and obesity research. Original research, review, case reports, hypothesis formation, expert opinion and commentaries are all considered for publication. The manuscript management system is completely online and includes a very quick and fair peer-review system, which is all easy to use. Visit http://www.dovepress.com/testimonials.php to read real quotes from published authors. 